\title{
THE GASTRIC NEUTRAL-RED EXCRETION TEST
}

\author{
BY \\ S. SEVITT \\ Department of Pathology, Birmingham Accident Hospital \\ AND \\ R. P. JEPSON \\ Surgical Professorial Unit, Manchester Royal Infirmary
}

(RECEIVED FOR PUBLICATION, MAY 18, 1948)

\section{Introduction}

The stomach's acid secretion is commonly used as a measure of gastric function, and various standardized tests have been devised. Owing, however, to the wide range of acid secretion in normal people, to the inconstant results obtained by repeating a test on many individuals, to the frequent occurrence of results well within the normal range in patients suffering from gastritis, gastric carcinoma, or peptic ulcer, and to the fact that from 10 to 20 per cent of normal people may have spontaneous temporary or permanent achlorhydria (Schiff, 1938 ; Palmer and others, 1940), estimation of the acid secretion of the stomach after a popularity of many years is now falling into disfavour as a diagnostic test.

In the search for a more reliable test, the excretory function of the gastric mucosa to various substances including dyes has been studied: one of these dyes is neutral red.

When a solution of neutral red is injected into a vein of a normal individual, the dye is excreted within a few minutes into the gastric juice, staining it pink: the concentration increases for a period and thereafter diminishes. During the next twenty-four to forty-eight hours the dye is excreted in the urine and colours the faeces.

In 1923 Glaessner and Wittgenstein introduced the excretion of neutral red by the stomach as a test of gastric function, but the normal variations were not worked out, nor was the relationship of dye excretion to acid secretion fully understood by these or subsequent workers (Davidson and others, 1925; Zibalis, 1934; Winklestein, 1942; Lourja and Mirkin, 1925). Twenty years later the excretion of neutral red by the stomach was reintroduced by Gillman $(1943,1944)$ as a test of gastric function. He used a standard technique whereby the rate of dye excretion and the rate and intensity of concentration of the dye in the gastric juice could be measured. He worked out the normal variations in healthy young European adults in Johannesburg, and showed that normal results were repeatable within narrow limits. By studying the results obtained on three hundred cases, mostly African natives with disturbed gastric function, he claimed to have established criteria of abnormality which could be of diagnostic and prognostic aid.

The intention of the present study was to check the range of normality reported by Gillman; to study the anatomy and physiology of neutral-red excretion; to compare the acid secretion of the stomach with its power to excrete dye, and to determine if the test could be of use in this country in the diagnosis of various gastric and duodenal disorders.

\section{Methods}

Technique of the neutral-red excretion (N.R.E.) test.-The Gillman method was adhered to with only minor modifications. A Ryle or Rehfuss tube was passed through the mouth into the stomach of the patient, who had fasted overnight. After the resting juice had been drawn off, the stomach was washed out with $100 \mathrm{ml}$. or more of warm water by means of a $20-\mathrm{ml}$. syringe until the aspirate became clear. When little or no mucus appeared in the washing, the stomach was emptied and was ready for the test. In a few cases, especially in carcinoma of the stomach, it was found difficult or impossible to obtain a clear and clean aspirate: these were cases with great excess of mucus in the juice, often together with altered blood.

Without delay, $5 \mathrm{ml}$. of a 1 per cent sterile neutralred aqueous solution was injected intravenously as rapidly as possible, and a stop-watch was started. Any remaining stomach contents were removed as soon as the injection was completed. Subsequent aspirations were carried out at 1-minute intervals 
until the dye first appeared in the juice. After that, aspiration was repeated every 2 minutes for the next 15 to 20 minutes, and later at 3- to 5-minute intervals. The period of the test was at least 30 minutes, and usually ten to fifteen aspirates were made. The entire volume of gastric contents obtainable was removed at each aspirate and placed in a test-tube of $5 / 8$ in. diameter upon which was marked the number of minutes from the time of the dye injection. The complete removal of the gastric contents before and immediately after injection and at subsequent aspirations was considered important; otherwise an unknown dilution factor would occur. Patients were instructed to expectorate and not to swallow saliva excreted during the test.

Difficulty in aspiration sometimes occurred: if the tube was blocked by a plug of mucus, injection of $20 \mathrm{ml}$. or more of air down the tube often cleared it: sometimes aspiration was facilitated by the patient bending forward.

The concentration of the dye in each sample of gastric juice was estimated by direct vision in a comparator box using standard dilutions of the dye contained in identical test-tubes. The standard tube was backed with a tube containing uncoloured juice, and the unknown with a tube of water. With a little practice the dilutions were easy to read.

The standards were kept in well-stoppered testtubes ready for use. Deterioration in colour was not appreciable for three or four months. The dye was made up in decinormal hydrochloric acid and the following dilutions used, viz., $1 / 300,000,1 / 200,000$, $1 / 100,000,1 / 75,000,1 / 50,000,1 / 30,000$, and $1 / 20,000$. The actual concentration of the dye was not usually recorded but the arbitrary scale of Trace, 1, 2, 3, 4, 5 , and 6 used by Gillman was adopted (Trace $=$ $1 / 300,000,1=1 / 200,000$, etc.). Graphic representation of each result was made by plotting dye concentration of the sample against the time in minutes (see Figure).

Further studies of the fasting juice and subsequent unstained and stained gastric fractions were carried out. The volumes were measured, the presence of mucus, bile, and macroscopic blood were noted, and benzidine tests for occult blood were performed. "Free hydrochloric acid" and "total acid" estimations were performed on the fasting specimen and on four or five samples of juice removed at consecutive 5- to 10-minute intervals. The dye was first removed from the sample by filtration through two or three thicknesses of filter paper, which absorbed the neutral red. Sometimes refiltration was necessary. Titration was carried out on $5 \mathrm{ml}$. (or if available $10 \mathrm{ml}$.) of the specimen with $\mathrm{N} / 10$ or $\mathrm{N} / 20$ sodium hydroxide, using a drop or two of a mixture of Töpfer's reagent and phenolphthalein as indicators. If achlorhydria was present, qualitative tests for pepsin were performed on two or three mixed samples of juice using coagulated egg-white as a substrate.

In some of the cases (vide infra) in which excretion of neutral red did not occur or was very poor within the first $\mathbf{3 0}$ minutes, aspirations were continued every 5 minutes for a further 30 to 60 minutes, sometimes after an intramuscular injection of $0.5 \mathrm{mg}$. of histamine.

Fractional test meals.-These were not performed on the twenty "control" cases, but were carried out on patients exhibiting gastric symptoms, usually a few days before the neutral-red excretion test was performed.

Absence of toxicity.-In the dosage used, neutral red was found to be free from toxic or unpleasant local or general effects. Its excretion in the urine and its colouring of the faeces within the following day or two was physiological. It was found advisable, however, to warn the nursing staff and the patient of this occurrence so as to prevent undue anxiety or alarm.

\section{Observations}

Results in N.R.E. tests in patients free from gastro-intestinal symptoms.-N.R.E. tests were performed on twenty in-patients of a military hospital who were free of any gastro-intestinal symptoms or signs. It was difficult to find perfectly healthy patients in hospital, but patient volunteers with various non-gastric disorders were selected They consisted of six convalescent minor surgical

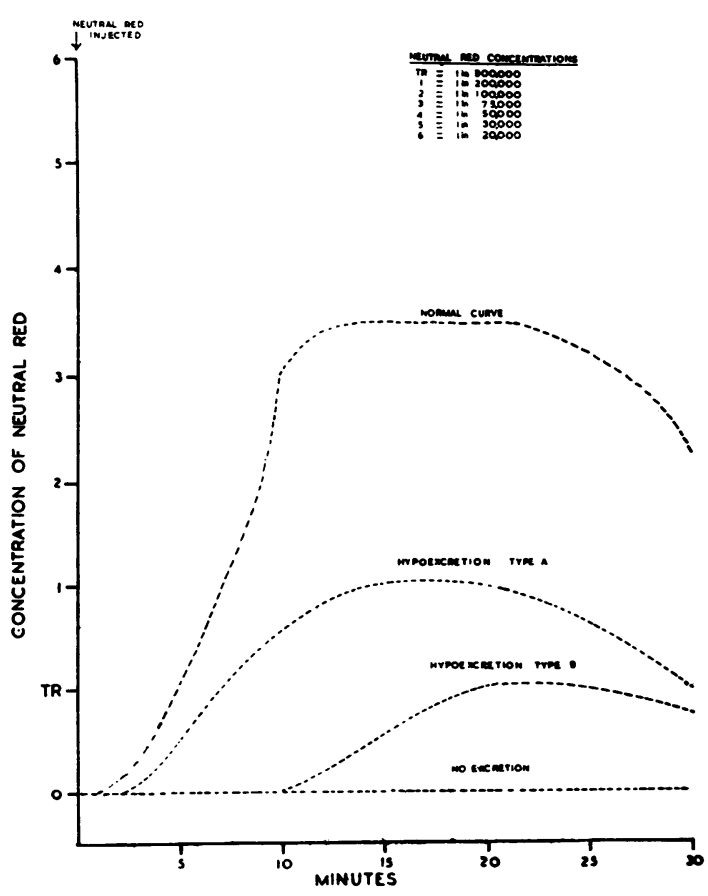

FIGURE.-Normal and abnormal neutral-red excretion curves. 


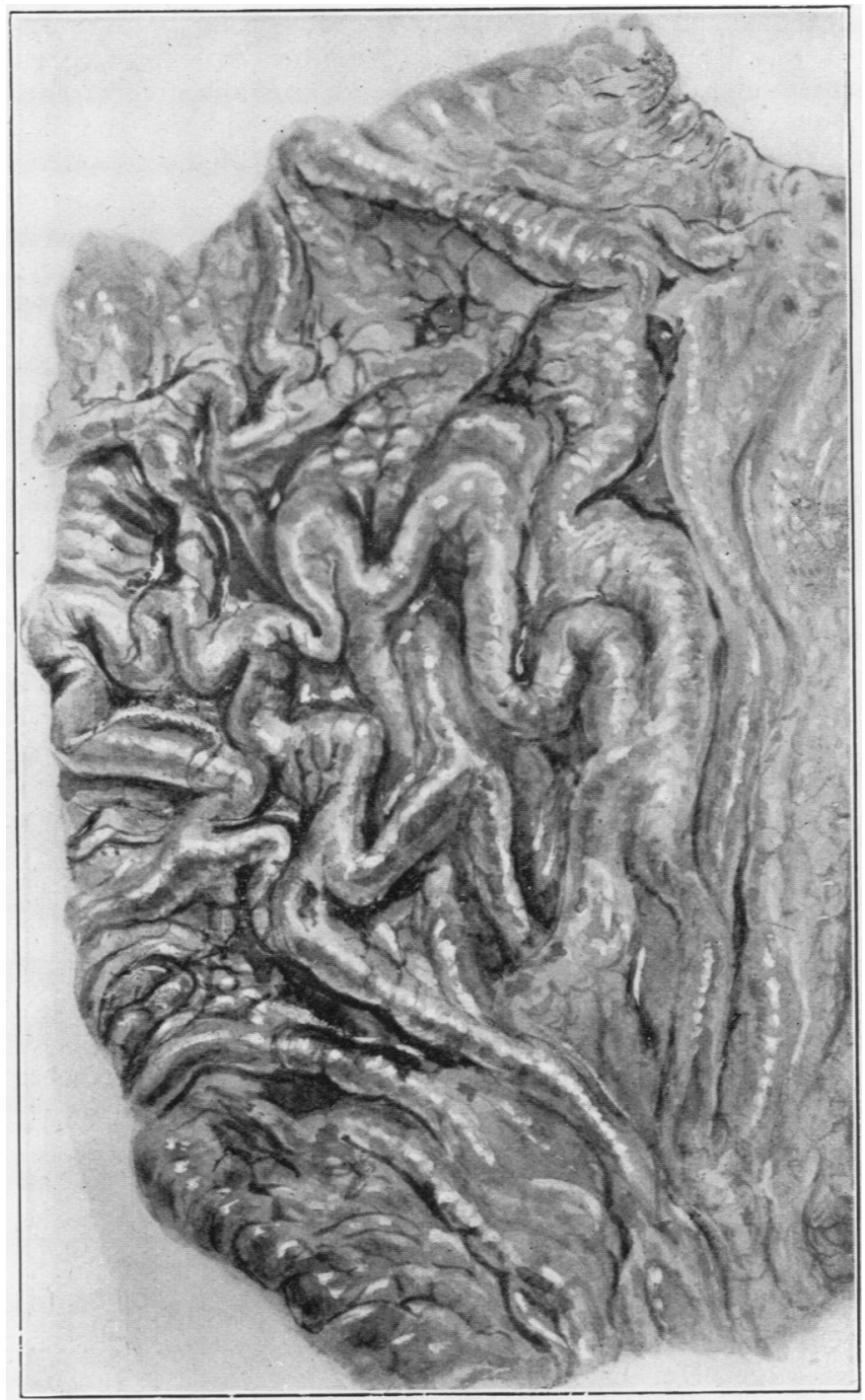

PLATE VIII.-Photograph of a colour drawing showing excretion of neutral red by the mucosa of the upper half of the body of the stomach (black streaks $=$ neutral red).

(Original drawing by Miss D. Davidson.) 
and fracture cases, three patients completely recovered from old head injuries, two mildly neurotic patients, and a case each of Bell's palsy, tinea pedis, convalescent atypical pneumonia, endometrosis, convalescent tonsillitis, progressive spastic palsy, congenital cystic disease of the lungs, and convalescent catarrhal jaundice. All these patients were out of bed; they were fit and well and had good appetites.

Only two of the patients were women; of the men, four were Germans, one an Italian, another a Pole, and the remainder were English, Scottish, or Irish. Two patients were 35 and 48 years of age respectively, the remainder 18 to 26 years old.

The details and shape of the N.R.E. curves were studied (see figure). The general shape of each curve was similar; dye tinged the juice a faint pink within a few minutes, and the concentration increased-usually quite rapidly - to reach a maximum which was maintained for a period and

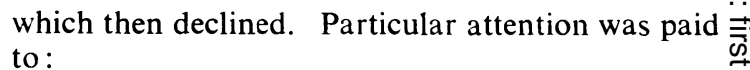

(1) The excretion time (E.T.), or the period in minutes between injection of the dye and its first appearance in the aspirate. In all cases this was 5 minutes or less. It is noteworthy that in seven $\bigcirc$ cases dye appeared within 1 minute, in thirteen $\approx$ within 2 minutes, and in seventeen cases within $\overrightarrow{0}$ 3 minutes of the injection.

(2) The concentration time (C.T.) or the period $\overrightarrow{\vec{\omega}}$ in minutes between injection of the dye and its $\stackrel{?}{?}$ earliest maximum concentration in the juice. In? fifteen cases this was between 8 and 12 minutes; $\vec{A}$ in the remainder it was $4,5,6,14$, and 19 minutes respectively.

(3) The maximum degree of concentration 음 found. $\left(\mathrm{C}_{\mathrm{M}}\right)$. Using the arbitrary scale of Trace, $\rightarrow$ $1,2,-6$ (see above), the $C_{M}$ in 15 cases was between 3 and 5 ; one was 6 , three were 2 , and one was 1.

TABLE I

RELATIONSHIP OF NEUTRAL-RED EXCRETION TESTS TO THE ACID SECRETION OF THE STOMACH

\begin{tabular}{|c|c|c|c|c|c|c|c|}
\hline Group of cases & $\begin{array}{l}\text { No. of } \\
\text { cases } \\
\text { in group }\end{array}$ & $\begin{array}{l}\text { Classification of } \\
\text { N.R.E. tests }\end{array}$ & $\begin{array}{c}\text { No. with } \\
\text { hyper- } \\
\text { acidity }\end{array}$ & $\begin{array}{c}\text { No. with } \\
\text { normal } \\
\text { acidity }\end{array}$ & $\begin{array}{l}\text { No. with } \\
\text { hypo- } \\
\text { acidity }\end{array}$ & $\begin{array}{l}\text { No. with } \\
\text { achlor- } \\
\text { hydria }\end{array}$ & Tota \\
\hline \multirow[t]{2}{*}{ Non gastric controls } & \multirow[t]{2}{*}{20} & Normal N.R.E. & 5 & 14 & 0 & 0 & 19 \\
\hline & & Hypo-excretory, Type a & 0 & 1 & 0 & 0 & 1 \\
\hline \multirow{3}{*}{$\begin{array}{l}\text { Carcinoma of } \\
\text { stomach }\end{array}$} & \multirow[t]{3}{*}{10} & Normal N.R.E. & 1 & 2 & 0 & 0 & 3 \\
\hline & & Hypo-excretory, Type b & 0 & 0 & 0 & 2 & 2 \\
\hline & & N.R. not excreted & 0 & 0 & 1 & 4 & 5 \\
\hline \multirow{3}{*}{$\begin{array}{l}\text { Chronic dyspepsia } \\
\text { and chronic gastri- } \\
\text { tis }\end{array}$} & \multirow[t]{3}{*}{11} & Normal N.R.E. & 0 & 4 & 1 & 0 & 5 \\
\hline & & Hypo-excretory, Type b & 1 & 1 & 0 & 0 & 2 \\
\hline & & N.R. not excreted & 0 & 1 & 0 & 3 & 4 \\
\hline \multirow[t]{3}{*}{ Peptic ulcer } & \multirow[t]{3}{*}{16} & Normal N.R.E. & 4 & 6 & 0 & 0 & 10 \\
\hline & & Hypo-excretory, Types a and b & 0 & 4 & 2 & 0 & 6 \\
\hline & & N R. not excreted & 0 & 0 & 0 & 0 & 0 \\
\hline \multirow[t]{3}{*}{ All Cases } & \multirow[t]{3}{*}{73} & Normal N.R.E. & 11 & 35 & 2 & 0 & 48 \\
\hline & & Hypo-excretory & 1 & 6 & 2 & 3 & 12 \\
\hline & & N.R. not excreted & 0 & 1 & 2 & 10 & 13 \\
\hline Totals & & & 12 & 42 & 6 & 13 & 73 \\
\hline
\end{tabular}


TABLE II

ANALYSIS OF CASES WITH ABNORMAL N.R.E. TESTS

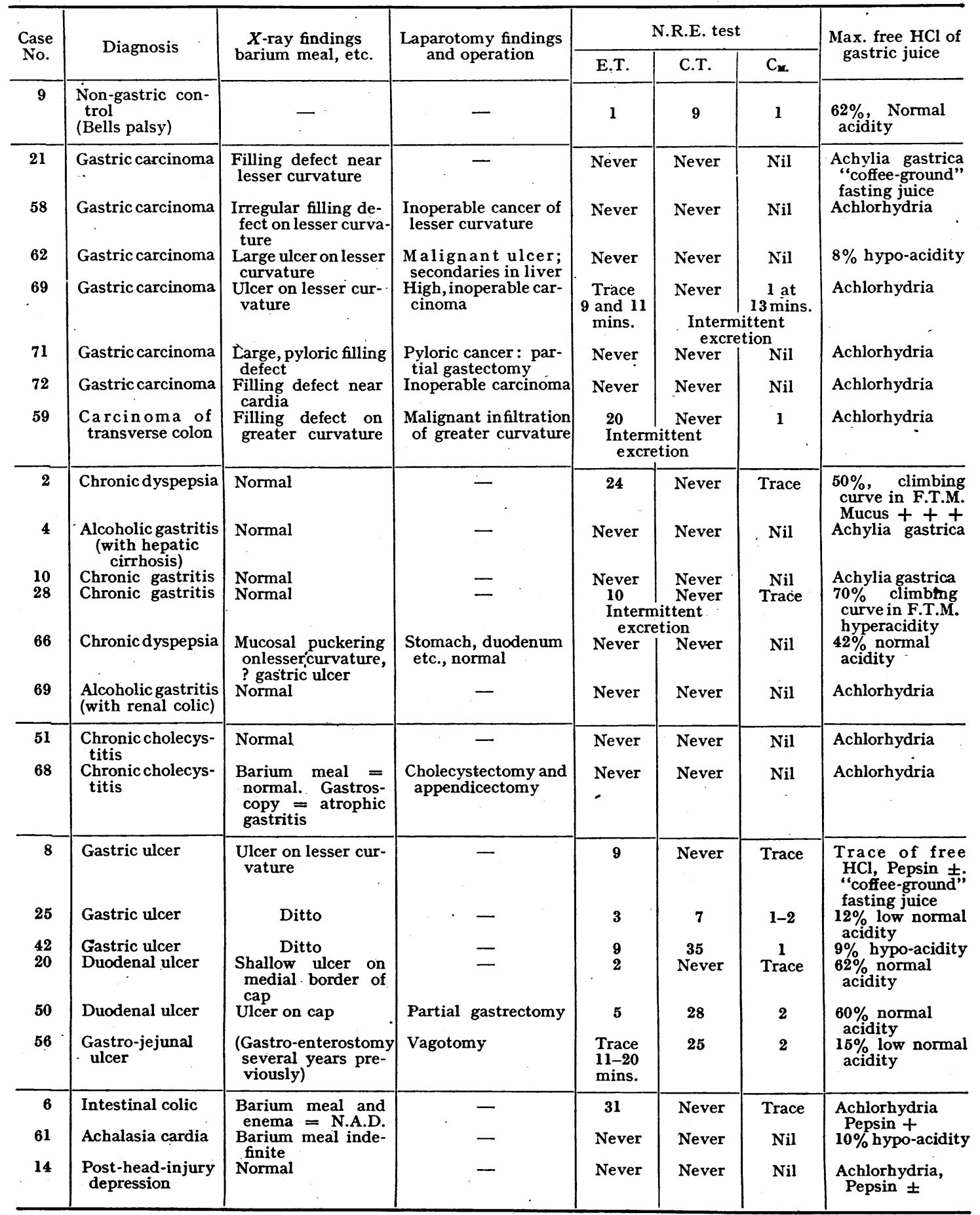


The normal curve of N.R. excretion.-Excluding one test, excretion of neutral red by the stomach began within 5 minutes of the injection; the dye was then concentrated to reach a maximum within 19 minutes, and the maximum concentration reached was between 2 and 6 . In the case of Bell's palsy showing a $C_{M}$ of 1 only, the E.T. was 1 minutes, C.T. 9 minutes (see Table II).

Except for the maximum degree of concentration, these results are in general agreement with those reported by Gillman (1944). He found that normal individuals excreted dye into the stomach within 10 minutes of the injection (usually 4 minutes) and concentrated it to an intensity of 4 to 6 within 20 minutes (average 14 minutes). If Gillman's maximum concentration is to be accepted, then the ten N.R.E. curves with a maximum of 3,2 , or 1 would be considered abnormal. None of these patients had any symptoms or signs of gastro-intestinal disorder, and they formed 50 per cent of the present " control" series.

It was arbitrarily decided to consider a $\mathrm{C}_{\mathrm{M}}$ of 1 as abnormally low and to define a normal N.R.E. curve as one in which dye is excreted within 10 minutes and reaches a maximum concentration of 2 to 6 within 20 minutes of intravenous injection of $5 \mathrm{ml}$. of 1 per cent neutral red.

Neutral-red excretion tests in patients with gastric or intestinal disorders.-Tests were performed in a military hospital and in the Professorial Surgical Unit, Manchester Royal Infirmary, on fifty-three patients with disturbed gastric or intestinal function. The cases fell into eight groups, viz.: gastric carcinoma, peptic ulcer, "duodenitis," gastric neurosis, lienteric diarrhoea, chronic dyspepsia including chronic gastritis and alchoholism, cholecystitis, and a miscellaneous group.

The ten patients with carcinoma of the stomach were all in the 40 to 70 years age group; six were men. In eight patients clinical and $x$-ray diagnosis was confirmed by laparotomy. One patient had primary carcinoma of the transverse colon with direct malignant infiltration of the greater curvature.

Of the sixteen patients with peptic ulcer, fourteen were men: six were under 30 , seven between 30 and 50 , and three were more than 50 years of age. Diagnosis of duodenal, gastric, or gastrojejunal ulcer was made by correlating clinical symptoms and signs with $x$-ray evidence following a barium meal. In ten cases laparotomy was performed and the diagnosis confirmed.

The three patients with "duodenitis" were all men under 30 years old. Diagnosis was made when classical symptoms of duodenal ulcer of $\stackrel{\vec{s}}{\vec{\rho}}$ recent origin were present, and when no $x$-ray evidence of peptic ulcer was found.

Of the four cases diagnosed as gastric neurosis, $\frac{\overline{\bar{s}}}{\sqrt{2}}$ three were men: all were under 25 years of age. $\mathbb{\otimes}$ In three an anxiety state was present: the other

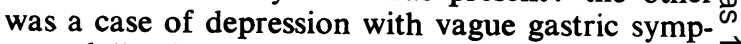
toms following a head injury.

The three cases with lienteric diarrhoea were all $\vec{\omega}$ young men: each gave a classical history of lien- $\omega$ teric and post-pandrial diarrhoea of several years' duration. Clinical and $x$-ray examinations were negative.

The chronic dyspepsia-gastritis group was a heterogenous group of ten men and one woman. Four were under 30 years of age, three between? 30 and 50, and the remainder older men. Three $\vec{\longrightarrow}$ of the patients were chronic alcoholics and had morning anorexia with flatulent dyspepsia (one $\frac{c}{\omega}$ also had mild polyneuritis and liver cirrhosis); the remainder gave a history of dyspepsia (flatulence $\vec{\varphi}$ and/or discomfort after meals) with or without $\stackrel{0}{0}$ anorexia of some years' duration. In some cases 0 the history was typical of chronic gastritis, but in others a satisfactory diagnosis could not be made. Cardiovascular disease was minimal or absent; and neither clinical nor $x$-ray examination was of positive help. In three cases, laparotomy revealed no abnormality.

The diagnosis of cholecystitis in one case (male, $\frac{3}{\supset}$ age 59 years) was made on clinical grounds and a negative barium meal radiograph: in the other (a woman, age 62 years), the barium meal radiograph showed diminished motility of the stomach, and gastroscopy an atrophic gastritis. At laparotomy, cholelithiasis was found and cholecystectomy and appendicectomy were performed.

The miscellaneous group were cases of subacute 옥 nephritis, repeated attacks of acute gastritis, $D$ achalasia of the cardia, and severe intestinal colic of unknown origin.

Results of N.R.E. tests. - Tests on twenty-nine of the fifty-three patients were within the normal $N$ range. The abnormal results fell into two groups, $\frac{\omega}{\sigma}$ viz.: those in which there was no excretion of dye into the stomach (anexcretory type) (13 cases), and those in which the dye was poorly concentrated $\stackrel{D}{\Phi}$ (11 cases). This group could be subdivided into two partially overlapping subgroups: (a) those with a normal E.T., $C_{M}$ less than 2 and a normal or delayed C.T., and (b) tests with normal or $\stackrel{\odot}{\mathbb{P}}$ delayed E.T. and $\mathrm{C}_{M} 1$ or less. The dye excretion $\unrhd$ in three was slight and intermittent. For descriptive purposes, these will be called hypo-excretory types $a$ and $b$. The figure portrays examples of 
these curves in contrast with a normal result, and one in which the dye was not excreted.

Table I classified the tests according to diagnosis, the non-gastric controls being included for comparison. Table II is a more detailed case and test analysis of the patients with abnormal N.R.E. tests.

Of ten patients with gastric carcinoma, five failed to excrete neutral red; in two excretion was poor and intermittent. Four of the eleven patients with chronic dyspepsia or gastritis did not excrete the dye, in two excretion was poor and delayed or intermittent. Both cases of cholecystitis were of the anexcretory type, but one patient also had atrophic gastritis. Of the sixteen peptic ulcer patients, ten had normal N.R.E. tests, the remainder hypoexcretory curves. Each case of "duodenitis" and lienteric diarrhoea, and three of the patients with gastric neurosis excreted neutral red normally. One of the latter (post head-injury depression) failed to excrete the dye. Of the four miscellaneous cases, the patient with achalasia of the cardia did not excrete neutral red and the patient with undiagnosed intestinal colic had only a very delayed and slight excretion of dye.

From these results it is clear that abnormal N.R.E. tests of the anexcretory and hypoexcretory types may occur in various organic disorders of the stomach and duodenum. Separate types of N.R.E. curves were not detected for particular diseases, and therefore the test cannot be of help in discriminating between (say) gastric carcinoma and gastritis. It is doubtful whether the test can distinguish between organic and functional disorder of the stomach, as cases of achalasia of the cardia (a local nervous disorder) and post-headinjury depression (with functional gastric symptoms) had anexcretory results. Moreover, normal N.R.E. tests can be given by patients with wellestablished organic disease of the stomach such as gastric carcinoma or peptic ulcer.

In practice the N.R.E. test is of value when an abnormal result is obtained: the conclusion may then be drawn that there is a disorder of the gastric mucosa of organic, functional, or possibly reflex origin.

Gillman (1944) found that normal results were repeatable after variable intervals of time. To confirm this, nine patients were subjected to a second test two to five weeks after the first. Seven had given normal N.R.E. curves on the first occasion and when repeated these tests were still within normal limits ; for example Case 3 (chronic gastritis) excreted neutral red at 3 minutes and concentrated it to a maximum of 2-3 in 14 minutes: five weeks later, excretion of dye began in 2 minutes and reached a maximum of 3 in 8 minutes. Two other patients failed to excrete the dye both at the first tests and when these were repeated a few weeks later.

Anatomy and physiology of neutral-red excretion.-Attempts were made to compare the blood level of the dye with its concentration in the gastric aspirate. In a patient with a blood volume of (say) 7 litres, the injection of $5 \mathrm{ml}$. of 1 per cent solution should produce a blood level of dye of about 1 in 140,000 or a plasma level of about 1 in 270,000 if all the dye remains in the plasma and if none diffuses into the extracellular tissues or is lost by excretion. In vitro experiments showed that when neutral red is added to oxalated whole blood, almost the entire quantity is present in the plasma, where its concentration could be estimated colorimetrically up to a concentration of 1 in 250,000 and detected up to 1 part per million.

Venous blood was removed from eight patients (from the arm opposite to the injection) 5 to 20 minutes after injection of the dye. In no case was it possible to detect neutral red in the plasma, although at the same time dye was being excreted in the juice in concentrations of $1 / 50,000$ to $1 / 200,000$. In two patients from whom blood was removed 5 and 6 minutes after injection, the dye was just appearing in trace concentration in the gastric juice. The urine was free from dye and it was considered impossible that excretion of dye could have been responsible for a plasma level of below 1 part per million. It was therefore concluded that neutral red rapidly diffuses into the extracellular tissues of the body, is present in a concentration of less than 1 in a million in the plasma, and is concentrated by the gastric mucosa during excretion at least 10 to 20 times.

In a patient with a duodenal ulcer (Case 49), the site of neutral-red excretion was established by a method suggested to one of us by Professor A. M. Boyd. This patient had an ulcer history of twenty years' duration, verified by barium meal $x$-ray examination. The fractional test meal showed hyperacidity and the N.R.E. test performed the day before the operation was normal (E.T. 2 minutes, C.T. 4 minutes, $C_{M}$ )).

Premedication with omnopon, 1/3 gr., and scopolamine, 1/150 gr., was given an hour and a half before operation which was carried out under ether anaesthesia. Partial gastrectomy was performed: during the course of the operation $5 \mathrm{ml}$. of 1 per cent neutral red was injected intravenously as soon as the greater curvature had been freed and the right gastric artery ligatured. Within a few minutes, the upper half of the gastric mucous membrane was stained red by the dye (see Plate 
VIII) and there was a fairly sharp line of demarcation halfway down the stomach below which no dye was excreted. The anexcretory area included the lower half of the body of the stomach, the pyloric antrum, and the pylorus. Excretion of dye still persisted when the surface was washed with saline.

Was the lack of the excretion in the lower half of the stomach due to tying the right gastric artery and freeing of the greater curvature? To exclude this possibility the injection of dye was repeated several times during the course of further gastrectomies for peptic ulceration and the same distribution of dye excretion was obtained notwithstanding when the dye was injected or its relationship to the tying of vessels.

Was the lack of excretion in the lower half due to antral gastritis? The gastric mucosa looked normal and subsequent histological examination of various areas including the antrum showed no abnormality.

Evidence of the nervous control of dye excretion was obtained in other cases. In a patient with a gastro-jejunal ulcer (see Table II, Case 56) there was a low normal gastric acidity before operation, and excretion of neutral red occurred although this was delayed and rather poor. Four weeks after a succcessful transpleural vagotomy the tests were repeated. No excretion of dye was found, and the patient had achlorhydria.

N.R.E. tests with normal results were performed on five patients, who for various reasons were later submitted to sympathectomy: three patients had unilateral and two bilateral sympathectomy from T 5 to $\mathbf{L} 3$ performed; splanchnicectomy was also carried out. The tests were repeated 2 to 3 weeks later and no significant changes in the excretion or concentration of dye by the stomach was found.

Several unsuccessful attempts were made both in rabbits and in man to discover the cellular origin of dye excretion. Biopsies of the stomach wall from the fundus, body and pylorus were taken within a few minutes of an intravenous injection of neutral red. The human material was collected during the course of partial gastrectomies. Frozen and paraffin sections were made and examinéd, stained and unstained, but no intracellular dye was seen even after treatment of the section with acid (neutral red is yellow in alkaline solution).

These results indicate that the excretion of neutral red is limited to the upper half of the gastric mucosa, that excretory activity is abolished by vagotomy, and that the sympathetic plays no part in the control of the excretion. The nervous control of the dye excretion and acid secretion is identical. Hydrochloric acid is secreted by the mucosa of the body of the stomach, probably over a wider area than that responsible for neutral-red excretion. The parietal (oxyntic) cells are not $\frac{C}{0}$ present in the pyloric region where an alkaline $\frac{\overline{\bar{\sigma}}}{\overline{3}}$ fluid is secreted. Stimulation of the vagus nerve $\widetilde{\Phi}$ in dogs produces a flow of strongly acid juice, $\frac{\Omega}{\sim}$ whilst stimulation of the sympathetic splanchnic ${ }^{\infty}$ nerves gives only a slow steady secretion of fluid $\vec{O}$ rich in mucus, often alkaline in relation (Pavlov, $\vec{\overrightarrow{ }}$ 1910 ; Carlson, 1923 ; Babkin, 1938). This latter secretion comes mainly from the pyloric glands and only to a minor extent from the body of the? stomach.

From similar anatomical sites of acid secretion and neutral-red excretion, and from their iden- $\vec{V}$ tical nervous control, it might be expected on 의 theoretical grounds that a relationship between acidsecretion and dye excretion exists, and that an abnormality in one property would be accompanied by a parallel abnormality in the other, for $\stackrel{\text { क }}{+}$ example achlorhydria with failure to excrete the $\vec{c}$ dye.

Relationship of acid secretion to neutral-red excretion by the gastric mucosa.-." Free" and "total" acid estimations were performed on specimens of gastric juice from all patients, including the controls. Forty of the cases with disturbed gastric or intestinal function had fractional test meals performed: in fifty cases acidity $\overrightarrow{0}$ was estimated on several specimens of gastric 3 juice obtained during the course of the N.R.E test, and in four of these acid estimations were performed on juice obtained after an injection of histamine.

Acid secretion of the stomach has a wide range of normality, and it is therefore difficult to deciden when abnormality begins. Arbitrary figures have to be adopted, and it was decided to accept a free acid equivalent to $70 \mathrm{ml}$. of $\mathrm{N} / 10$ hydrochloric acid per cent ( 70 per cent) as the limit of the uppe range. Similarly the limit of the lower range was accepted as a free acid volume of $10 \mathrm{ml}$. of $\mathrm{N} / 10 \mathrm{~W}$ hydrochloric acid per cent (10 per cent). If one or more fractions of juice had a value of 70 pep cent or over, hyperacidity was said to be present if all the specimens of juice analysed were less? than 10 per cent, hypo-acidity was said to exist.

From an examination of Tables I and II it is clear that the ability of the stomach to excrete neutral red and to secrete hydrochloric acid are not necessarily allied. Six patients (Cases 2, 9, 20 25,50 , and 56) with normal acid production hade hypo-excretory dye curves, one patient with hyper $\mathbb{D}$ acidity excreted the dye poorly (Case 28); and another (Case 66) with normal acid production 
failed to excrete the dye at all. Gillman's (1944) statement that patients with very poor or no excretion of dye are always achlorhydric is incorrect. However, there is a statistical correlation between normal acid production and normal neutral-red excretion and between achlorhydria and lack of excretion of dye. This relationship is probably the reflection of a common anatomical mucosal site for secretion and excretion and of a common nervous control of these activities.

\section{Conclusions and Summary}

The excretion of neutral red by the normal gastric mucous membrane follows the same pattern in different people within fairly narrow and easily recognized limits. Normality and abnormality in dye excretion is readily established using the neutral-red excretion test standardized by Gillman. When the test is repeated on the same individual, identical or closely similar results are obtained whether dye excretion is normal or abnormal. Rarely is an abnormal N.R.E. test given by a patient with a healthy gastric mucosa, and it can be said that abnormality in excretion of the dye is strongly suggestive of disordered gastric function.

For these reasons the N.R.E. test is superior and more reliable than the estimation of acid secretion. Other material advantages include safety, simplicity, and the short time it occupies. Furthermore, the dye and the apparatus are easily obtained, and if necessary the test can be performed by the clinician at the bedside.

All investigators agree that total failure to excrete neutral red is diagnostic of gastric dysfunction and many (Lourja and Mirkin, 1925; Morrison, 1938 ; Gillman, 1944) that partial suppression of dye excretion is an abnormal result preceding the final stage of total suppression. Whilst the present investigation is in the main in agreement with these observations, there is no doubt that patients with various disorders of the stomach and duodenum, including carcinoma and peptic ulcer, may have normal dye excretion. This may occur notwithstanding the duration of the disorder or the severity of the condition. A normal result is then of no value in distinguishing a normal from a pathological stomach, and the test is not nearly as sensitive as Gillman suggests.

Furthermore, neither a normal nor an abnormal result is of diagnostic use in differentiating between cancer, gastritis, and other conditions. Although the results of the peptic ulcer series suggest that complete suppression of excretion does not occur in cases of simple ulcer, this may not be true and may result from pure chance in the selection of the cases. Functional disorder of reflex or nervous origin may or may not suppress excretory function, so that the N.R.E. test is of no value in distinguishing organic from non-organic disease.

The problem of serial tests on the same patient to determine the deterioration or recovery from gastric disorder was not studied.

Although a statistical relationship exists between excretion of neutral red and secretion of acid, the correlation has exceptions and in any individual case disorder of one function may or may not be accompanied by a parallel disorder of the other.

Finally, experiments and observation indicate that, following the injection of neutral red, most of the dye rapidly diffuses into the extracellular tissue fluid and is present in the blood in minute undetectable traces (concentration $<1$ part per million) although at the same time it is being excreted by the gastric mucosa in concentrations up to 1 in 50,000 . The parasympathetic vagus nerves are probably the excitory nerves controlling dye excretion, and the sympathetic plays no part in the activity.

The investigations of one of us (S.S.) were carried out at the Military Hospital for Head Injuries, Wheatley, Oxford, and of the other (R.P.J.) in the Professorial Surgical Unit, Manchester Royal Infirmary. We are indebted to many clinical and laboratory colleagues and to members of the nursing staff of both hospitals for their co-operation and assistance. In particular we wish to thank Dr. J. Bull for his statistical assistance in the analysis of part of Table II, Prof. A. M. Boyd for his timely suggestions and co-operation during the pursuance of the work in Manchester, and Miss D. Davidson for her excellent drawing. We are indebted to Lieut.-Col. E. H. Hall, R.A.M.C., A.D.P. Southern Command, for his interest. We acknowledge the permission of the Army Medical Department, War Office, to publish this investigation.

\section{REFERENCES}

Babkin, B. P. (1938). Amer. J. digest. Dis., 5, 467.

Carlson, A. J. (1923). Physiol. Rev., 3, 1.

Davidson, P. B., Willcox, E., and Haagensen, C. D. (1925). J. Amer. med. Ass., 85, 794.

Giliman, T. (1943). S. Afr. J. med. Sci., 8, 50

Gillman, T. (1944). Gastroenterology, 3, 188.

Glaessner, K., and Wittgenstein, H. (1923). Klin. Wschr., 2, 1650.

Lourja, R. A., and Mirkin, A. I. (1925). Arch. Verdauungskrankheiten, 34, 5 .

Morrison, S. (1938). Amer. J. digest. Dis., 5, 617

Palmer, W. L., Kirsner, J. B., and Nutter, P. B. (1940). Amer. J. digest. Dis., 7, 427 .

Pavlov, I. P. (1910). "Work of Digestive Glands." Second ed. Griffin: London.

Schiff, L. (1938). Arch. intern. Med., 61, 774.

Winklestein, A. (1942). Amer. J. med. Sci., 203, 419.

Wright, Samson (1941). “Applied Physiology." Seventh edition, Oxford University Press.

Zibalis, S. (1934). Pr. Med., 42, 1260. 